\title{
Comunicação \\ Efeito da adubação nitrogenada na produção de mudas de lichieira
}

\author{
Ronny Clayton Smarsi ${ }^{1}$, Gabriella Ferreira de Oliveira ${ }^{2}$, Luis Lessi Dos Reis ${ }^{1}$, Edvan Alves Chagas ${ }^{3}$, Rafael Pio ${ }^{4}$, \\ Vander Mendonça ${ }^{5}$, Pollyana Cardoso Chagas ${ }^{6}$, Paula Nogueira Curi ${ }^{7}$
}

\section{RESUMO}

Devido à falta de informações sobre a aplicação de nitrogênio na produção de mudas de licheira na fase de viveiro, o experimento foi conduzido em viveiro no município de Urânia-SP (20¹1'25,4”'S e 50³7'42,9”' O). O delineamento experimental utilizado foi de blocos ao acaso, com cinco tratamentos, que consistiram em doses de nitrogênio aplicadas na forma de uréia $(45 \%$ de $\mathrm{N})\left(0,800,1.600,2.400,3.200 \mathrm{mg} \mathrm{dm}^{-3}\right.$ de substrato) com quatro repetições e dez plantas por parcela. Após 104 dias do início do experimento, foi avaliado o comprimento da parte aérea e do sistema radicular, número de folhas e o teor de clorofila. Houve efeito significativo das doses de $\mathrm{N}$ apenas para comprimento da parte aérea e teor de clorofila. $\mathrm{Na}$ adubação nitrogenada de mudas de licheira, a dose de $2.188,33 \mathrm{mg} \mathrm{dm}^{-3}$ de $\mathrm{N}$ no substrato proporcionou o maior comprimento da parte aérea das plantas. O teor de clorofila nas folhas das mudas de lichia aumentou linearmente com o aumento das doses de nitrogênio.

Palavras-chave: Litchi chinensis Sonn, propagação, nitrogênio.

\section{ABSTRACT}

\section{Nitrogen fertilization in the productionof lychee seedlings}

Because the lack of information on nitrogen application in the production of lychee seedlings in the nursery stage, the present work was carried out in a nursery in the municipality of Urânia-SP $\left(20^{\circ} 11^{\prime} 25.4^{\prime \prime}\right.$ S and $\left.50^{\circ} 37^{\prime} 42.9^{\prime \prime} \mathrm{W}\right)$. The experiment was arranged in a randomized block design with five treatments (five rates of nitrogen in form of urea - $45 \%$ N): 0, 800, 1600, 2400 and $3200 \mathrm{mg} \cdot \mathrm{dm}^{-3}$ of substrate, with four replications and ten plants for replication. One hundred and four days days after planting, the length of aerial part and roots, number of leaves and content of chlorophyll were evaluated. There was significant effect of $\mathrm{N}$ rates only for length of aerial part and chlorophyll content. Nitrogen fertilization of lychee seedlings at the concentration of $2188.33 \mathrm{mg}_{\mathrm{dm}}{ }^{3}$ of $\mathrm{N}$ in the substrate provided the greatest length of the aerial part. Chlorophyll content in the leaves increased linearly with nitrogen rates.

Key words: Litchi chinensis Sonn., propagation, fertilization, seedlings, nitrogen.

\footnotetext{
Recebido para publicação em setembro de 2009 e aprovado em dezembro de 2010

Graduandos em Agronomia. Universidade Estadual do Mato Grosso do Sul (UEMS), Rod. MS 306, Km 06, 79540-000, Cassilândia, MS. ronnycs1@ @otmail.com lessireis@ yahoo.com.br

${ }^{2}$ Graduanda do Curso de Biologia. Faculdade de Engenharia de Ilha Solteira, Av. Brasil, 56, Centro, C.P. 31, 15385-000, Ilha Solteira, SP. gaby_unesp@yahoo.com.br

${ }^{3}$ Engenheiro-Agrônomo, D.Sc., Empresa Brasileira de Pesquisa Agropecuária (EMBRAPA CPAFRR), Rodovia 174, Km 8, Caixa Postal 133, 69301-970, Boa Vista, RR. echagas@cpafrr.embrapa.br

${ }^{4}$ Engenheiro-Agrônomo, D.Sc., Departamento de Agricultura, Universidade Federal de Lavras (UFLA), Caixa Postal 3037, 37200-000, Lavras, MG. Autor para correspondência rafaelpio@hotmail.com

${ }^{5}$ Engenheiro-Agrônomo, D.Sc., Departamento de Fitotecnia, Universidade Federal Rural do Semi-Árido (UFERSA), BR 110, Km 47, Pres. Costa e Silva, 59625-900, Mossoró- RN vander@ufersa.edu.br

${ }^{6}$ Engenheiro-Agrônomo, M.Sc., Departamento de Agricultura, Universidade Federal de Lavras (UFLA), Caixa Postal 3037, 37200-000, Lavras, MG. pcchagas.eagro.ufrr@ hotmail.com ${ }^{7}$ Engenheiro-Agrônomo, Departamento de Agricultura, Universidade Federal de Lavras (UFLA), Caixa Postal 3037, 37200-000, Lavras, MG. paulanogueiracuri@yahoo.com.br
} 


\section{INTRODUÇÃO}

A lichieira (Litchi chinensis Sonn.) é uma planta da família Sapindaceae, a mesma do guaraná, pitomba e rambutã. É uma fruteira tipicamente de clima subtropical. No Brasil sua introdução se deu no ano de 1810 no Rio de Janeiro, a partir daí seu cultivo se expandiu para a região Sudeste (Bastos et al., 2004).

A produção brasileira atual de lichia não está bem determinada, concentrando-se principalmente no estado de São Paulo, na região da Alta Paulista. Na Companhia de Entrepostos e Armazéns Gerais de São Paulo (CEAGESP), 97\% das lichias comercializadas são fornecidas pelo Estado de São Paulo e é realizada nos meses de novembro, dezembro, janeiro e meados de fevereiro (Bastos et al., 2004).

Um dos grandes entraves no cultivo comercial da lichia é a obtenção de mudas com a qualidade desejada e com padrão de mercado. De maneira geral, as mudas são obtidas via processo de alporquia, pois, aquelas oriundas de sementes possuem a desvantagem de apresentarem um longo período improdutivo ocasionado pela fase de juvenilidade (Hartmann et al., 2002). Outro inconveniente a ser ressaltado é a grande variabilidade genética dos cultivares, o que resultam em plantas com acentuadas diferenças de vigor no campo e qualidade dos frutos produzidos, sugerindo-se a necessidade de propagação clonal ou vegetativa (Yee, 1957; Fachinello et al., 2005).

Dentre os principais aspectos relacionados ao processo de implantação do pomar, a escolha de mudas vigorosas e de qualidade torna-se o principal aspecto relacionado à iniciação de um pomar. Sendo assim as mudas de lichieira produzidas por propagação vegetativa, via alporquia, reduz o período de juvenilidade ( 5 a 6 anos) das plantas no campo e pemite a obtenção de plantas geneticamente idênticas às matrizes (Bastos et al., 2004; Smarsi et al., 2008).

Com relação à adubação, existem dificuldades para a recomendação de fertilização específica para a lichieira, devido a carência de investigações científicas. Dessa forma, têm sido adotadas recomendações que assegurem o suprimento de nutrientes das mais exigentes, tendo, assim, as demais espécies a sua demanda atendida (Cruz et $a l .$, 2006). O aspecto nutricional na produção de mudas deve ser considerado criteriosamente para que as mudas não venham a ter seu crescimento prejudicado pela falta ou desbalanço de nutrientes (Gonçalves, 2000).

A aplicação de nitrogênio $(\mathrm{N})$ para as plantas geralmente é feita com uréia, sulfato de amônio ou nitratos. Segundo Scivittaro et al. (2004) a uréia destaca-se entre as fontes comerciais de nitrogênio no sistema de produção de mudas, pela facilidade de acesso no mercado, menor custo por unidade de N, elevada solubilidade e com- patibilidade para uso em mistura com outros fertilizantes. No entanto, é bastante suscetível a perdas por volatilização de amônia e apresenta efeito ácido no substrato.

Trabalhos relacionados com a lichieira, incluindo toda a cadeia produtiva são incipientes no Brasil. Sendo assim, quaisquer pesquisas que venham contribuir para o avanço da cultura são importes. Neste sentido, a definição de um programa adequado de fertilização de mudas de lichieira pode melhorar o conhecimento técnico sobre a cultura. Assim, conduziu-se o presente estudo, objetivando avaliar o crescimento e desenvolvimento de mudas de lichieira em doses crescentes de nitrogênio.

\section{MATERIAL E MÉTODOS}

O experimento foi conduzido em viveiro com tela de sombreamento de $50 \%$, na Chácara Nossa Senhora Aparecida, município de Urânia-SP (latitude 20 $11^{\prime}$ ' 25,4" $\mathrm{S}$, longitude $50^{\circ} 37^{\prime} 42,9^{\prime \prime} \mathrm{O}$ ) e altitude média de $415 \mathrm{~m}$.

O período de execução foi de janeiro a abril de 2007 . O material vegetal utilizado foi obtido através da propagação vegetativa pelo método de alporquia em ramos semilenhosos da variedade Bengal, produzidos no mês de outubro de 2006 e transplantados para os sacos de polietileno com dimensões de $15 \mathrm{~cm}$ de largura por $25 \mathrm{~cm}$ de altura, com volume de 1,4 L, após dois meses. O substrato utilizado foi constituído de terra de barranco e esterco bovino (proporção 3:1), acrescido de $100 \mathrm{~g}$ de calcário dolomítico e $100 \mathrm{~g}$ de cloreto de potássio.

Foram avaliadas cinco doses de nitrogênio: 0, 800, $1.600,2.400,3.200 \mathrm{mg} \cdot \mathrm{dm}^{-3}$, utilizando-se uréia como fonte de nitrogênio ( $45 \%$ de N). Realizaram-se quatro aplicações por tratamento com intervalo de dez dias (dose do tratamento dividida em quatro parcelas), sendo a primeira aplicação iniciado após o surgimento da segunda folha da brotação emitida na estaca. Durante a condução do experimento, realizaram-se os tratos culturais rotineiros, a exemplo da irrigação manual duas vezes ao dia e remoção das plantas daninhas.

O delineamento experimental utilizado foi de blocos ao acaso, com cinco tratamentos (doses de N), quatro blocos e dez plantas por parcela. Após 104 dias da instalação, as plantas foram retiradas dos sacos plásticos, lavadas em água corrente e secas ao ar livre. Em seguida, avaliaram-se os comprimentos da parte aérea e das raízes $(\mathrm{cm})$, o número de folhas e o teor de clorofila (CCI). Posteriormente, as plantas foram separadas em parte aérea e raízes e colocadas em estufa com circulação forçada de ar, a $65^{\circ} \mathrm{C}$ por 72 horas, até atingirem o peso constante, para em seguida serem mensuradas, com auxilio de balança digital de precisão a massa seca dos componentes: raiz, parte aérea e massa seca total.

Os dados obtidos foram submetidos à análise de variância e as médias dos níveis de Nitrogênio, submeti- 
das à análise de regressão polinomial. As análises foram realizadas utilizando-se o programa computacional SISVAR (Sistema para Análise de Variância).

\section{RESULTADOS E DISCUSSÃO}

Com relação ao comprimento da parte aérea das mudas verificou-se que houve um efeito quadrático à medida que se elevou a dose de $\mathrm{N}$ aplicadas via adubação de cobertura (Figura 1). As mudas de lichieira apresentaram um aumento no comprimento da parte aérea atingindo 40,57 $\mathrm{cm}$, quando submetida à dose de $2.188,33 \mathrm{mg} . \mathrm{dm}^{-3} \mathrm{de} \mathrm{N}$ no substrato, a partir do qual observou-se um efeito negativo da adubação nitrogenada no crescimento das mudas. Na máxima dosagem testada (3.200 mg.dm ${ }^{-3}$ de $\left.\mathrm{N}\right)$ não verificou-se um incremento no comprimento da parte aérea quando as plantas forma submetidas a maiores doses de nitrogênio.

O efeito depressivo na altura das mudas quando adubadas com doses acima de 2.188,33 mg. $\mathrm{dm}^{-3}$ de $\mathrm{N}$ pode ter ocorrido em função de algum desequilíbrio nutricional causado pelo excesso do $\mathrm{N}$ nas plantas. Conforme relatam Decarlos Neto et al. (2002), este efeito depressivo pode ser devido também à diminuição do $\mathrm{pH}$ do substrato, através da liberação de $\mathrm{H}^{+}$produzidos durante o processo de nitrificação da uréia aplicada.

As respostas das doses de $\mathrm{N}$ para o teor de clorofila das mudas de lichieira, apresentaram comportamento linear crescente à medida que se eleva a dose de $\mathrm{N}$ testada. Assim, verificou-se que a dose de $3.200 \mathrm{mg}^{-\mathrm{dm}^{-3}} \mathrm{de} \mathrm{N}$ no substrato, proporcionou um teor de clorofila de $26,17 \mathrm{CCl}$ (Figura 2). Esse resultado está de acordo com inúmeros outros autores, os quais observaram, trabalhando com diversas espécies, que o aumento do teor de clorofilas nas folhas estão diretamente relacionados com a elevação do teor de nitrogênio nas folhas (Malavolta, 2006). Apesar do maior teor de clorofila observados nas folhas, esse resultado não contribuiu para o maior comprimento da parte aérea.

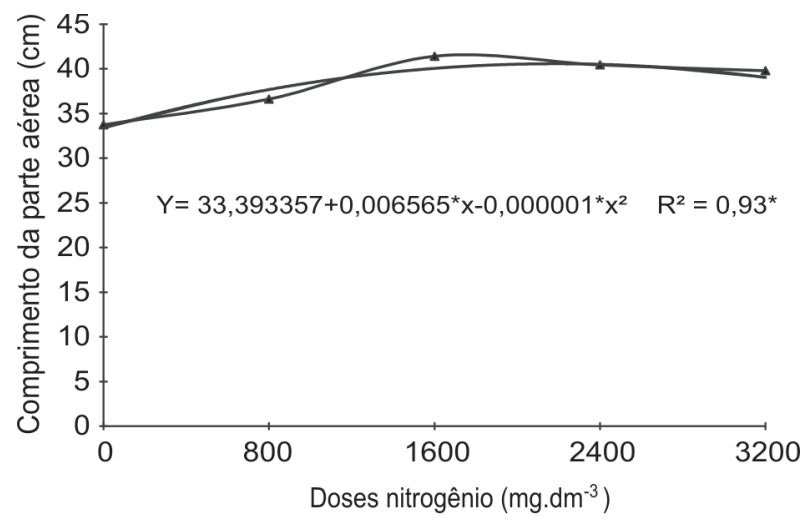

Figura 1. Comprimento da parte aérea das mudas de lichia quando submetidas a diferentes doses de $\mathrm{N}$.

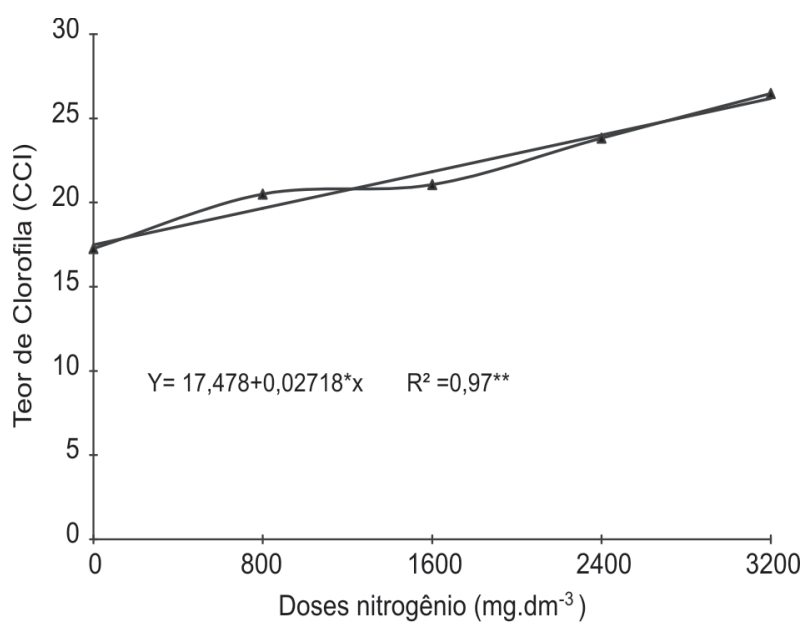

Figura 2. Teor de clorofila das mudas de lichia quando submetidas a diferentes doses de $\mathrm{N}$.

\section{CONCLUSÃO}

Conclui-se que na adubação nitrogenada de mudas de licheira, a dose de $2.188,33 \mathrm{mg} \cdot \mathrm{dm}^{-3}$ de $\mathrm{N}$ no substrato proporcionou o maior comprimento da parte aérea das plantas; o teor de clorofila nas folhas das mudas de lichia aumentou linearmente com o aumento das doses de nitrogênio.

\section{REFERÊNCIAS}

Bastos DC, Scarpare Filho JA, Fatinansi JC, Pio R \& Spósito MB (2004) A cultura da lichia. Piracicaba, DIBD/ESALQ. 23p. (Boletim técnico, 26).

Cruz CAF, Paiva HN \& Guerrero CRA (2006) Efeito da adubação nitrogenada na produção de mudas de sete-cascas (samanea inopinata (harms) ducke). Árvore, 30:537-546.

Decarlos Neto A, Siqueira DL, Pereira PRG \& Alvarez VH (2002) Crescimento de porta-enxertos de citros em tubetes influenciados por doses de N. Revista Brasileira de Fruticultura, 24(2):199203.

Fachinello JC, Hoffmann A \& Nachtigal JC (2005) Propagação de plantas frutíferas. Brasília, Embrapa. 221 p.

Gonçalves JLM (2000) Produção de mudas de espécies nativas: substrato, nutrição, sombreamento e fertilização. In: Gonçalves JLM \& Benedeti V (Eds.). Nutrição e fertilização florestal. Piracicaba, IPEF. p.309-350.

Hartmann HT, Kester DE, Davies Junior FT \& Geneve RL (2002) Plant propagation: principles and practices. 7. ed. New Jersey, Prentice Hall. 880p.

Malavolta E (2006) Manual de nutrição mineral de plantas. São Paulo,: Editora Agronômica Ceres. 638 p.

Scivittaro WB, Oliveira RP \& Morales CFG (2004) Adubação nitrogenada na formação de porta-enxertos de limoeiro 'cravo' em tubetes. Revista Brasileira de Fruticultura, 26(1):131-135.

Smarsi RC, Chagas EA, Reis LL, Oliveira GF, Mendonça V, Tropaldi L, Pio R \& Scarpare Filho JÁ (2008) Concentrações de ácido indolbutírico e tipos de substrato na propagação vegetativa de lichia. Revista Brasileira de Fruticultura, 30(1):07-11.

Yee W (1957) The lychee in Hawaii. Extension Circular Hawaii Agricultural Experiment Station, 366:1-13.

Rev. Ceres, Viçosa, v. 58, n.1, p. 129-131, jan/fev, 2011 